Article

\title{
The Immobilization of ChEMBL474807 Molecules Using Different Classes of Nanostructures
}

\author{
Przemysław Czelen * (D) and Beata Szefler ${ }^{\mathbb{D}}$ \\ Department of Physical Chemistry, Faculty of Pharmacy, Collegium Medicum, Nicolaus Copernicus University, \\ Kurpinskiego 5, 85-096 Bydgoszcz, Poland \\ * Correspondence: przemekcz@cm.umk.pl
}

Received: 24 June 2019; Accepted: 23 July 2019; Published: 2 August 2019

\begin{abstract}
Indirubin derivatives and analogues are a large group of compounds which are widely and successfully used in treatment of many cancer diseases. In particular, the ChEMBL474807 molecule, which has confirmed inhibiting abilities against CDK2 and GSK3B enzymes, can be included in this group. The immobilization of inhibitors with the use of nanocarriers is an often used strategy in creation of targeted therapies. Evaluations were made of the possibility of immobilizing ligand molecules on different types of nanocarrier, such as carbon nanotubes (CNT), functionalized fullerene $\mathrm{C}_{60}$ derivatives (FF_X), and functionalized cube rhombellanes, via the use of docking methods. All results were compared with a reference system, namely $\mathrm{C}_{60}$ fullerene. The realized calculations allowed indication of a group of compounds that exhibited significant binding affinity relative to the ligand molecule. Obtained data shows that structural modifications, such as those related to the addition of functional groups or changes of structure symmetry, realized in particular types of considered nanostructures, can contribute to increases of their binding capabilities. The analysis of all obtained nano complexes clearly shows that the dominant role in stabilization of such systems is played by stacking and hydrophobic interactions. The realized research allowed identification of potential nanostructures that, together with the ChEMBL474807 molecule, enable the creation of targeted therapy.
\end{abstract}

Keywords: indirubin analogs; docking; rhombellanes; fullerenes; ChEMBL474807; $\mathrm{C}_{60}$; carbon nanotubes

\section{Introduction}

Indirubin is a natural compound which can be found as a component of natural indigo, and for many years has been well known as an ingredient used in many traditional medicine methods. Its applications are numerous and related to its pharmacological potential, manifesting through anti-inflammatory [1], antitumor [2,3], antiangiogenic [4], and neuroprotective [5] effects. Indirubin and its derivatives or analogues are also well known as competitive ATP inhibitors; such inhibiting potential has also been confirmed in the case of cyclin-dependent kinases (CDK) and glycogen synthase kinase 3 (GSK3) [6,7], and contributed to the development of promising drugs for diabetes, inflammation, cancer, and neurodegeneration [5,8-11]. The ChEMBL474807 molecule can be included in this group of compounds, since its inhibitory properties against CDK2 and GSK3B have been confirmed with the use of molecular modeling methods [12]. The direct application of compounds with pharmacological potential can be fraught, with many potential side effects related, for example, to toxicity or wide spectrum of impact. One of the most commonly used strategies for prevention of such phenomena is the preparation of targeted therapy involving the use of carriers providing controlled release of drugs. Such therapies not only increase the efficiency and bioavailability of the drugs used, but also often reduce the occurrence of side effects [13-17]. The chemical structure of the ChEMBL474807 ligand molecule is presented in Figure 1. Four cyclic systems containing three 
aromatic rings indicate that one of the most important stabilizing effects in interactions with potential carriers should be stacking or hydrophobic interactions. The presence of four hydrogens which could play the role of hydrogen bond donors also is worth taking into account. A large group of commonly used carriers are compounds included in the group of fullerenes or their derivatives. One of the most intensively used fullerene molecules is $\mathrm{C}_{60}$. Numerous studies have shown significant binding potential of this particle in the context of $\pi-\pi$ stacking interactions with many biologically active compounds [18]. The chemical structure of such a molecule also enables free penetration through cell membranes $[17,19,20]$, however, small concentrations of this compound are non-toxic for living organisms $[13,21-23]$. The structure of the $\mathrm{C}_{60}$ molecule exhibits structural disproportion compared to the considered ligand molecule, and the lack of any hydrogen bond acceptors also encourages the search for new nanostructures that could better utilize the binding potential of the inhibitor.

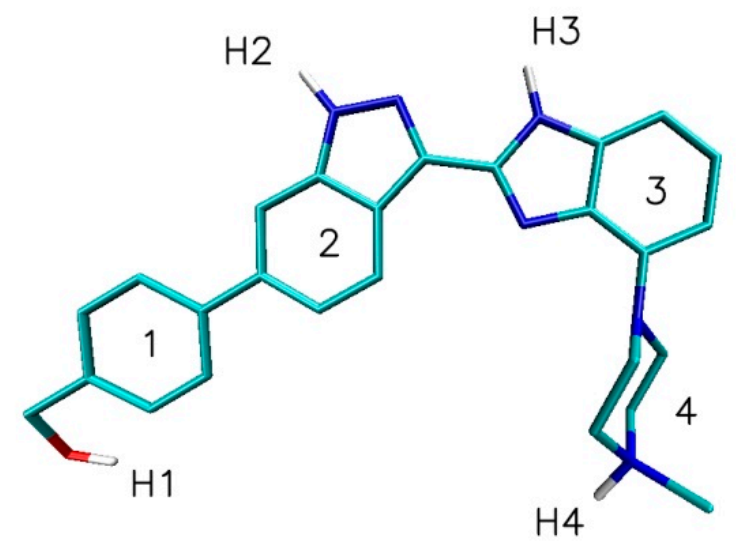

Figure 1. Graphic representation of ligand molecule.

The most intuitive solution seems to be analysis of the functionalized derivatives of $\mathrm{C}_{60}$ fullerene, which have found numerous applications in modern medicine [24-26]. Table S1 presents sets of chemical structures and names of proposed fullerenes. In this group of nanocarriers, compounds with single and multiple substituents placed on the surface of C60 fullerene can be found. The scope of the functional groups used takes into account aliphatic chains with methoxy, amide, ester, and halogen groups, and aromatic systems that include unsubstituted benzene rings, as well as more complex aromatic systems. The next set of nanosystems worthy of consideration is carbon nanotubes, which have found many applications in the biomedical field e.g., in diagnostics, tissue engineering, or targeted drug delivery [27-29]. The characteristic structure of these nanosystems is created by rolling up graphene sheets, and such large surfaces consisting of aromatic systems could exhibit high affinity toward the considered ligand molecule that exhibiting significant activity in stacking interactions. The last interesting group of nanocarriers are the cube rhombellane (Cube-rbl) homeomorphs, consisting of a molecule core and a second shell created by eight modules connected with the structure by three chemical bonds, e.g., ester or amide [30-33]. The examples of such structures created by Diudea are presented in Figure 2. The proposed nanostructures, due to their characteristic modular structures, provide numerous active groups arranged on a nanocarrier surface in an organized manner, strictly dependent on the symmetry of the molecule core. Depending on the type of the particular molecule, the active groups are aromatic rings or cyclohexane derivatives and ester or amide groups. The precise characteristics of all Cube-rbl are displayed in Table S2. The evaluation of ligand molecule affinity relative to all proposed nanocarriers can contribute to the creation of effective targeted therapy. 


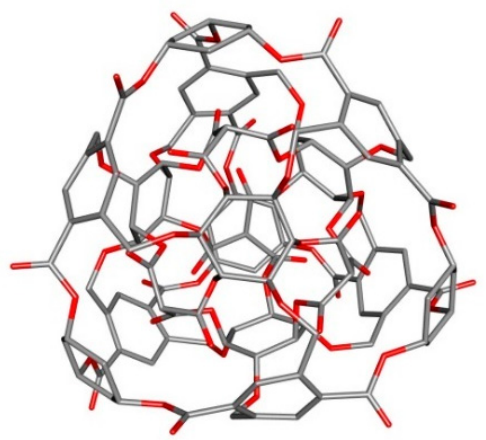

$308 \mathrm{a}$

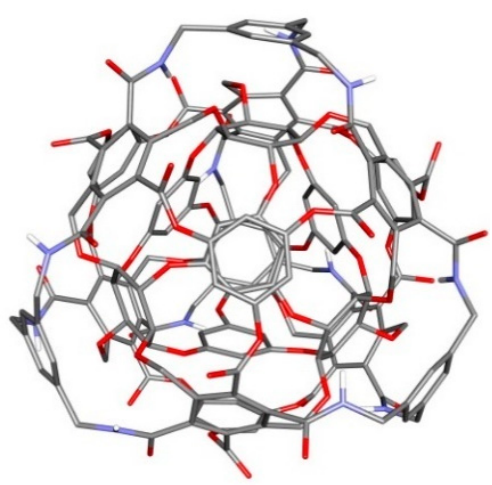

372

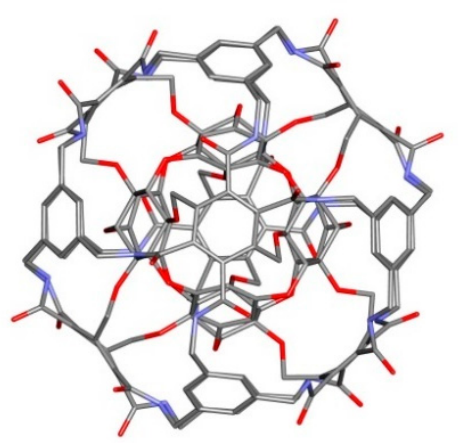

420

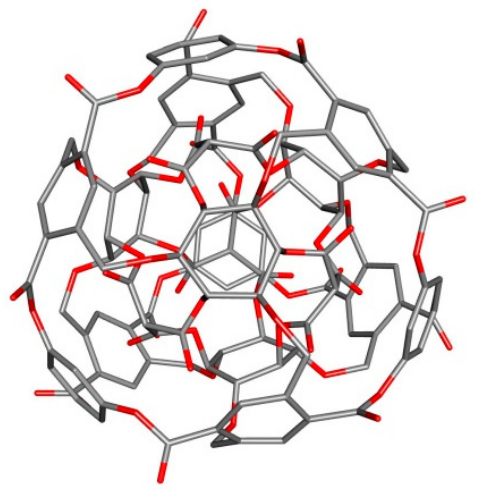

$308 b$

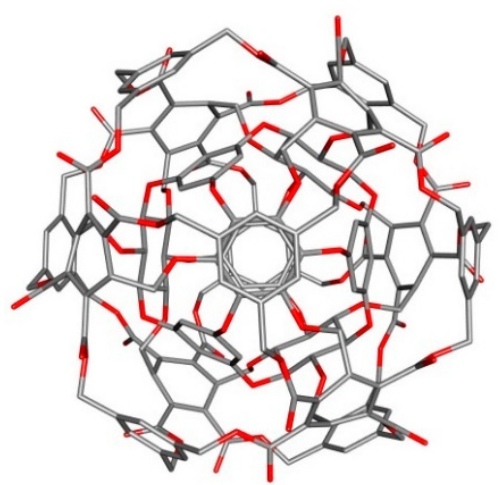

396

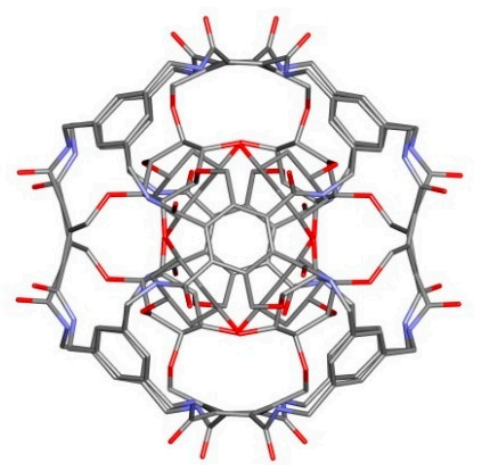

444
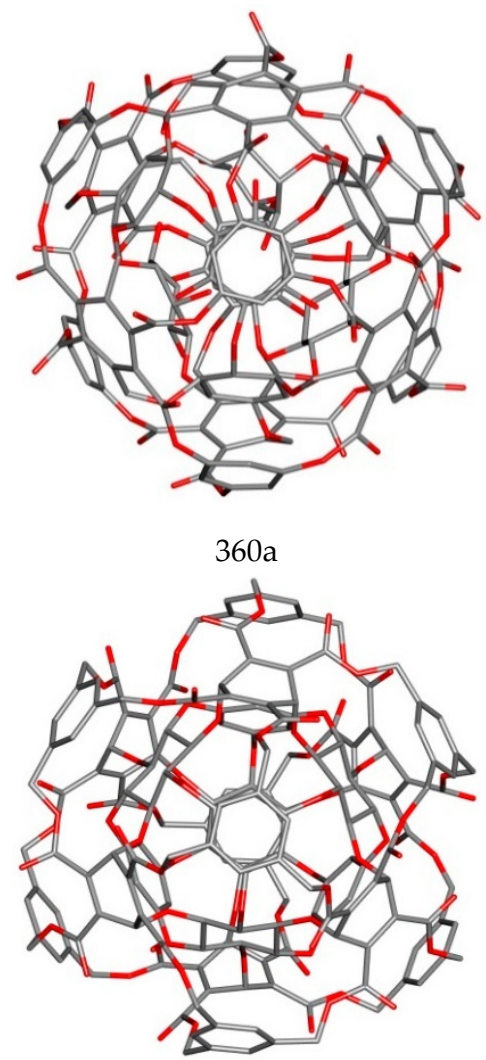

$360 \mathrm{~b}$

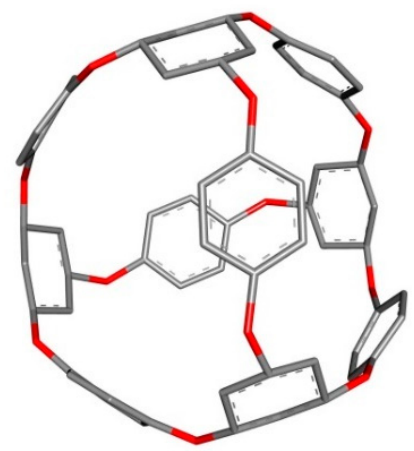

ADA132

Figure 2. Graphic representation of the chosen structures of cube rhombellane homeomorphs.

\section{Methods}

The ligand molecule, namely ChEMBL474807 (1-(4-amino-1,2,5-oxadiazol-3-yl)-5-(piperidin-1ylmethyl)- $N^{\prime}$-(pyridin-4-ylmethylene)-1H-1,2,3-triazole-4-carbohydrazide), was obtained from CHEMBL Database [34]. Rhombellane homeomorphs, were obtained from Topo Cluj Group [33], the $\mathrm{C}_{60}$ structure was downloaded from Brookhaven Protein Database PDB [35], and $\mathrm{C}_{60}$ functionalized derivatives were obtained from the PubChem database [36]. The carbon nanotubes described in Table 1 were generated using the VMD package [37], chosen values of " $n$ " and " $m$ " vectors allowed for the creation of different types of nanotubes characterized by similar diameter values. The AutoDockVina program and implemented united-atom scoring function was used during the docking stage [38]. 
Table 1. Description of carbon nanotube parameters used during docking stage.

\begin{tabular}{cccccccc}
\hline $\begin{array}{c}\text { Nanostructure } \\
\text { Name }\end{array}$ & C Atoms & $\begin{array}{c}\text { N chiral } \\
\text { Index }\end{array}$ & $\begin{array}{c}\text { M Chiral } \\
\text { Index }\end{array}$ & L [nm] & Type & D [A] & $\begin{array}{c}\text { Diameter } \\
\text { Class }\end{array}$ \\
\hline CNT_260 & 260 & 5 & 5 & 3 & armchair & 6.25 & D1 \\
CNT_252 & 252 & 6 & 3 & 3 & chiral & 6.21 & D1 \\
CNT_256 & 256 & 8 & 0 & 3 & zigzag & 6.73 & D1 \\
CNT_416 & 416 & 8 & 8 & 3 & armchair & 10.83 & D2 \\
CNT_392 & 392 & 10 & 6 & 2 & chiral & 10.94 & D2 \\
CNT_448 & 448 & 14 & 0 & 3 & zigzag & 10.94 & D2 \\
CNT_676 & 676 & 13 & 13 & 3 & armchair & 17.47 & D3 \\
CNT_760 & 760 & 15 & 10 & 3 & chiral & 17.01 & D3 \\
CNT_704 & 704 & 22 & 0 & 3 & zigzag & 17.20 & D3 \\
\hline
\end{tabular}

During the docking stage, ligand and nanosystem structures containing only polar hydrogen atoms were used. In the case of all "spherical" nanoparticles, the grid box dimensions were established equal to $26 \times 26 \times 26 \AA$, while in the case of carbon nanotubes, sets of values were chosen that ensured free interactions of the ligand molecule with the surface and interior of the nanosystems used. All initial procedures related to preparation of the ligand and nanosystems during the docking procedure were realized with the use of AutoDock Tools package [39]. All calculations during the docking stage were realized with an exhaustiveness parameter equal to 20 , since such a value ensures an appropriate reproducibility of the results and a reasonable time of calculation. Structural analysis of the considered systems and visualization of the obtained complexes were realized with use of the VMD package [37]. The value of the binding constant was calculated based on the formula:

$$
K_{\max }=\exp ^{\left(\frac{-\Delta G \max }{R T}\right)}
$$

where $\Delta G_{\max }$ represents maximal value of binding affinity obtained during docking stage, $R$ represents value of gas constant, and $T$ represents temperature.

\section{Results and Discussion}

The affinity of a ligand molecule towards different classes of nanocarrier was evaluated with the use of docking methods. The carbon nanoparticle most often used as a nanocarrier is the $\mathrm{C}_{60}$ molecule, therefore, it was used as a reference system in this study. The binding affinity of the considered ligand molecule towards native $\mathrm{C}_{60}$ molecules was equal to $-4.90 \mathrm{kcal} / \mathrm{mol}$ (Table 2). The structure of the obtained complex presented in Figure 3 shows that the long structure of the ligand molecule has limited ability to interact with fullerene $\mathrm{C}_{60}$ and cannot effectively use all aromatic systems in creation of interactions. The observed single stacking interaction of one of the aromatic systems of the ligand molecule cannot strongly stabilize the analyzed complex. Table 2 also presents the values obtained for functionalized $\mathrm{C}_{60}$ fullerenes. Structural changes observed in the considered molecules were related to the addition of various functional groups, including aliphatic chains with methoxy, amide, ester, and halogen groups supporting the possibility of creation of hydrogen bonds and aromatic systems that include unsubstituted benzene rings, as well as more complex aromatic systems (Table S1). All considered compounds exhibited much higher binding affinity towards ligand molecule than native $C_{60}$ fullerene, which manifested in the increase of these values by -1.0 to $-3.1 \mathrm{kcal} / \mathrm{mol}$. The differences in binding affinity were more evident in the context of the binding constant of complex formation $\left[K_{\max }\right]$, for which the observed increase relative to the reference system started from $440 \%$ and in the best cases even reached $18,621 \%$ (Table 2). The most interesting outcomes were obtained for functionalized fullerenes containing aromatic substituents. The presence of a single aromatic group increased the values of binding affinity by at least $-1.7 \mathrm{kcal} / \mathrm{mol}$. The possibility of additional stabilizing impacts significantly affected the durability of considered complexes. Graphic representations of the most interesting complexes are shown in Figure 3. The presence of a single aromatic functional group 
on the surface of functionalized $\mathrm{C}_{60}$ molecule, observed for example in the case of FF_5, FF_7, FF_8, and FF_11 molecules, forced a characteristic orientation of the ligand molecule. The first aromatic system of the ligand molecule interacted with aromatic systems from functional groups of the considered fullerenes, and the observed planar orientations, with distances in the range of 3.63 to $3.68 \AA$, indicated strong stacking interactions. The next stabilizing impact was related to the second aromatic system of the ligand molecule, the orientation of which enabled interactions with the aromatic surface of the fullerene core, and, in this case, the distances between aromatic systems were smaller and fell in the range of 3.48 to $3.57 \AA$. The conformation of ligand molecules in the considered complexes caused the third aromatic system to be unable to actively interact with the surface of the fullerenes. The last stabilizing impact was related to the fourth cyclic system of the ligand molecule, of which the orientation enabled the appearance of hydrophobic interactions with the fullerene surface. The addition of multiple aromatic systems on the fullerene surface, like in the case of FF_12, significantly increased the stability of the obtained complexes; this was confirmed by the values of the binding constant $\left[K_{\max }\right]$, which reached values $18,621 \%$ higher than the reference system. The presence of multiple aromatic substituents on the fullerene surface of the FF_12 molecule allowed all aromatic systems of the ligand molecule to be engaged in the creation of stacking interactions (Figure 3). Many functionalized fullerenes used during the docking stage contained hydrogen bond acceptors, however, the creation of such interactions with any polar hydrogen atom of the ligand molecule was not observed in any case. Such an observation clearly indicates the dominant role of stacking and hydrophobic interactions in stabilization of ligand complexes with functionalized fullerenes.

Table 2. Values of binding affinity $[\mathrm{kcal} / \mathrm{mol}]$ of ligand molecule relative to functionalized $\mathrm{C}_{60}$ fullerene derivatives $\left(\mathrm{FF} \_\mathrm{X}\right)$ obtained during docking stage.

\begin{tabular}{|c|c|c|c|c|c|c|}
\hline \multirow{2}{*}{$\begin{array}{l}\text { Nanostructure } \\
\text { Name }\end{array}$} & \multicolumn{4}{|c|}{$\Delta \mathrm{G}[\mathrm{kcal} / \mathrm{mol}]$} & \multirow{2}{*}{$\begin{array}{c}\text { Binding Constant } \\
{\left[\mathrm{K}_{\max }\right]}\end{array}$} & \multirow{2}{*}{$\begin{array}{l}\text { Difference of } K_{\max } \\
\text { Relative to } C_{60}[\%]\end{array}$} \\
\hline & MAX & MIN & AVERAGE & SD & & \\
\hline FF_1 & -6.50 & -6.00 & -6.24 & 0.13 & $58,151.8$ & 1388.7 \\
\hline FF_2 & -6.10 & -5.80 & -5.96 & 0.09 & $29,604.6$ & 657.9 \\
\hline FF_3 & -6.50 & -6.10 & -6.31 & 0.11 & $58,151.8$ & 1388.7 \\
\hline FF_4 & -6.00 & -5.90 & -5.95 & 0.05 & $25,006.8$ & 540.2 \\
\hline FF_5 & -7.10 & -6.50 & -6.74 & 0.16 & $160,091.8$ & 3998.5 \\
\hline FF_6 & -6.10 & -5.70 & -5.85 & 0.13 & $29,604.6$ & 657.9 \\
\hline FF_7 & -6.80 & -6.40 & -6.57 & 0.10 & $96,486.4$ & 2370.1 \\
\hline FF_8 & -6.70 & -6.30 & -6.50 & 0.12 & $81,501.4$ & 1986.5 \\
\hline FF_9 & -6.60 & -6.40 & -6.48 & 0.07 & $68,843.7$ & 1662.4 \\
\hline FF_10 & -6.10 & -5.70 & -5.82 & 0.11 & $29,604.6$ & 657.9 \\
\hline FF_11 & -7.20 & -6.70 & -6.92 & 0.15 & $189,526.5$ & 4752.0 \\
\hline FF_12 & -8.00 & -7.40 & -7.66 & 0.18 & $731,270.0$ & $18,621.0$ \\
\hline FF_13 & -5.90 & -5.80 & -5.83 & 0.05 & $21,123.1$ & 440.8 \\
\hline $\mathrm{C}_{60}$ & -4.90 & -4.90 & -4.90 & 0.00 & 3906.1 & 0.0 \\
\hline
\end{tabular}




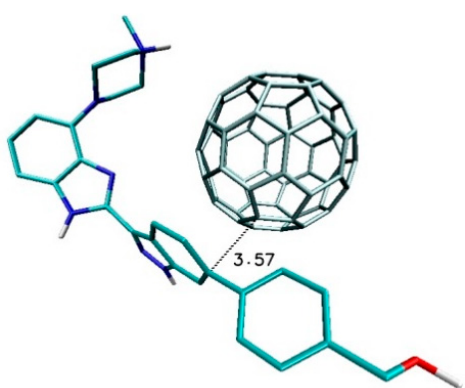

$\mathrm{C}_{60}$

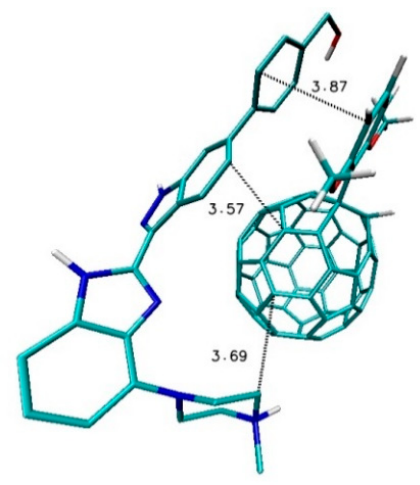

FF_8

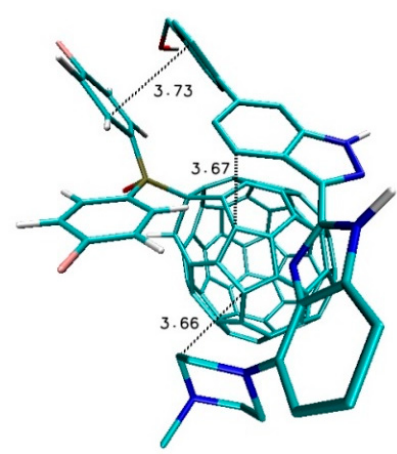

FF_5

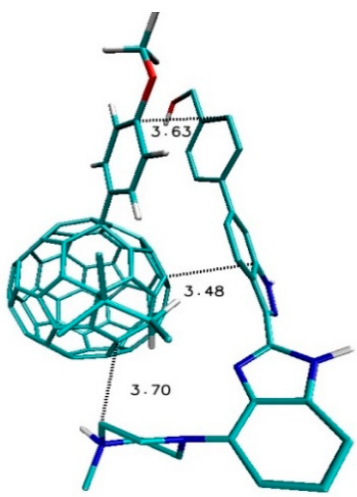

FF_11

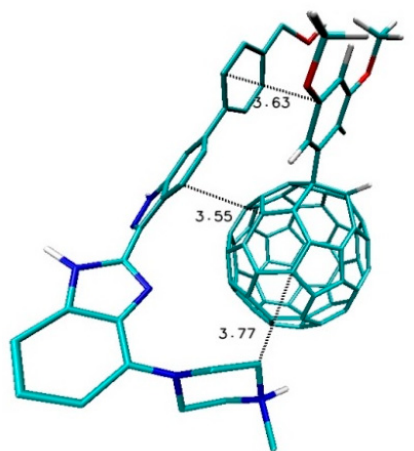

FF_7

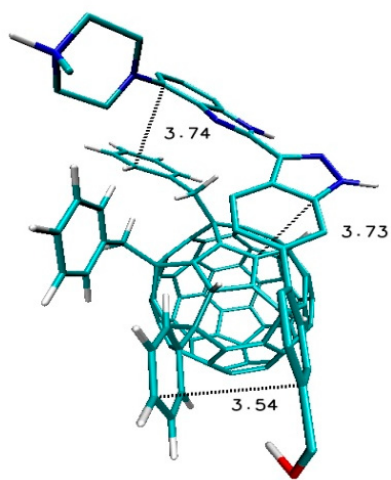

FF_12

Figure 3. Graphic representation of ligand complexes with functionalized derivatives of $C_{60}$ fullerene characterized by highest binding affinity.

The next class of nanostructures used during modeling were carbon nanotubes. Three types of such nanosystems were used, namely zigzag $(n, 0)$, armchair $(n, n)$, and chiral $(n, m)$, with each set of vector parameters defining the way the graphene sheet is rolled. Appropriate graphic representations for each type of nanotube are shown in Figure 4. The values presented in Table 3 describe the affinity of the ligand molecule for each type of nanotube considered, characterized by three different diameter values. For each nanotube, the ligand affinity relative to the surface and interior of the considered nanosystem was evaluated. In the context of interaction with the surface of nanotubes, one of the most important factors is the nanotube diameter, and presented data clearly show that three classes of systems can be distinguished.

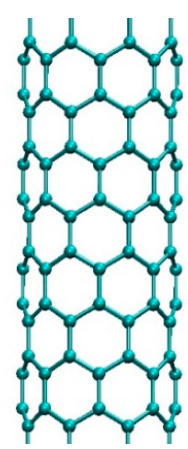

Zigzag

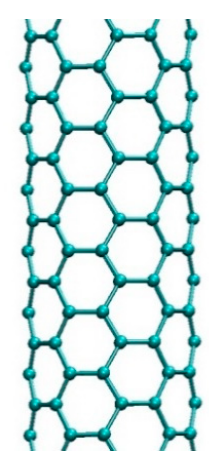

armchair

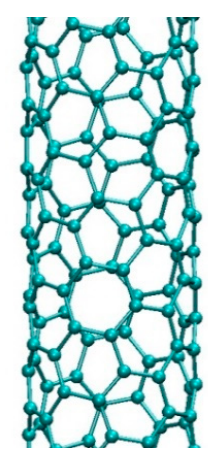

chiral

Figure 4. Graphic representation of nanotube structure types. 
Table 3. Values of binding affinity $[\mathrm{kcal} / \mathrm{mol}]$ of the ligand molecule relative to carbon nanotubes (CNT) obtained during docking stage. The values presented in italics are positive and indicate the non-physical character of the interactions of the ligand molecule with the interior of the nanotube with smallest diameter.

\begin{tabular}{|c|c|c|c|c|c|c|}
\hline \multirow{2}{*}{$\begin{array}{l}\text { Nanostructure } \\
\text { Name }\end{array}$} & \multicolumn{4}{|c|}{$\Delta \mathrm{G}[\mathrm{kcal} / \mathrm{mol}]$} & \multirow{2}{*}{$\begin{array}{c}\text { Binding Constant } \\
{\left[\mathrm{K}_{\max }\right]}\end{array}$} & \multirow{2}{*}{ Type } \\
\hline & MAX & MIN & AVERAGE & SD & & \\
\hline \multicolumn{7}{|c|}{ CNT surface } \\
\hline CNT_260 & -10.8 & -10.6 & -10.7 & 0.06 & $8.25 \times 10^{7}$ & armchair \\
\hline CNT_252 & -10.5 & -10.3 & -10.4 & 0.06 & $4.97 \times 10^{7}$ & chiral \\
\hline CNT_256 & -10.4 & -10.3 & -10.4 & 0.05 & $4.20 \times 10^{7}$ & zigzag \\
\hline CNT_416 & -11.6 & -11.4 & -11.5 & 0.06 & $3.18 \times 10^{8}$ & armchair \\
\hline CNT_392 & -11.7 & -11.5 & -11.6 & 0.07 & $3.77 \times 10^{8}$ & chiral \\
\hline CNT_448 & -11.6 & -11.5 & -11.6 & 0.05 & $3.18 \times 10^{8}$ & zigzag \\
\hline CNT_676 & -12.6 & -12.4 & -12.5 & 0.05 & $1.72 \times 10^{9}$ & armchair \\
\hline CNT_760 & -12.6 & -12.4 & -12.5 & 0.05 & $1.72 \times 10^{9}$ & chiral \\
\hline CNT_704 & -12.5 & -12.4 & -12.4 & 0.05 & $1.45 \times 10^{9}$ & zigzag \\
\hline \multicolumn{7}{|c|}{ CNT interior } \\
\hline CNT_260 & 134.9 & 142 & 138 & 2.6 & $1.31 \times 10^{-99}$ & armchair \\
\hline CNT_252 & 249.9 & 269 & 257 & 10.9 & $6.62 \times 10^{-184}$ & chiral \\
\hline CNT_256 & 232 & 271 & 257 & 21.7 & $8.74 \times 10^{-171}$ & zigzag \\
\hline CNT_416 & -19 & -18.9 & -18.9 & 0.02 & $8.46 \times 10^{13}$ & armchair \\
\hline CNT_392 & -19.4 & -19.2 & -19.3 & 0.09 & $1.66 \times 10^{14}$ & chiral \\
\hline CNT_448 & -19.1 & -19 & -19 & 0.05 & $1.00 \times 10^{14}$ & zigzag \\
\hline CNT_676 & -18.3 & -18.2 & -18.2 & 0.04 & $2.59 \times 10^{13}$ & armchair \\
\hline CNT_760 & -18.5 & -18.3 & -18.4 & 0.06 & $3.64 \times 10^{13}$ & chiral \\
\hline CNT_704 & -18.4 & -18.3 & -18.4 & 0.04 & $3.07 \times 10^{13}$ & zigzag \\
\hline
\end{tabular}

Increasing nanotube diameter and the related reduction of their surface curvature clearly affected the affinity relative to the ligand molecule. For each change of nanotube diameter from $\sim 6 \AA$ to $\sim 11 \AA$ and to $\sim 17 \AA$, simultaneous increases of binding affinity by about $-1 \mathrm{kcal} / \mathrm{mol}$ were observed. In the case of two classes of nanotubes characterized by higher diameter values, the type of nanotube did not influence the affinity toward the ligand. Another situation was observed for nanotubes characterized by the smallest diameter values, as in this case, differences in affinities of particular types of nanotubes occured. Relatively large nanotube surface curvatures preferred the "armchair" type, which exhibited the highest affinity toward the ligand molecule. Differences of about $-0.4 \mathrm{kcal} / \mathrm{mol}$ relative to other types of nanotubes indicated that the binding constant for that complex was twofold higher. The structures of the ligand molecule complexes with the chosen nanotubes are presented in Figure 5. In the case of systems where the ligand molecule interacted with the surface of the nanotube, a longitudinal orientation of considered molecules was always observed, regardless of the diameter of the nanotube. This orientation was dominant for all considered complexes. The planar orientation of the ligand molecule in all complexes and distances placed in the range from 3.43 to $3.74 \AA$ caused all aromatic systems of the ligand molecule to be involved in creation of stable stacking interactions with the surfaces of the nanotubes used. The next analyzed aspect is related to interaction of the ligand molecule with nanotube interior. In this case, only two classes of nanotubes supported a sufficient diameter for this goal $(\sim 11 \AA, \sim 17 \AA)$. The data presented in Table 3 show that nanosystems with a smaller diameter (D2) interacted with the ligand molecule much more strongly, and the differences in binding affinities between the compared systems were in the range of -0.7 to $-0.9 \mathrm{kcal} / \mathrm{mol}$. The structures of complexes created by two compared classes of nanotubes were also significantly different (Figure 5 ). In the case of class D3, linearly arranged ligand molecule interacted with an internal nanotube surface, while in the case of class D2 nanotubes, centrally located ligand molecules could interact with the upper and lower plane of the molecule with nanotube walls. Additionally, the presence of aliphatic cyclic systems did not allow for an energetically favorable conformation to be obtained completely localized inside the nanotube. This part of the ligand interacted with the edge of the nanotube. 


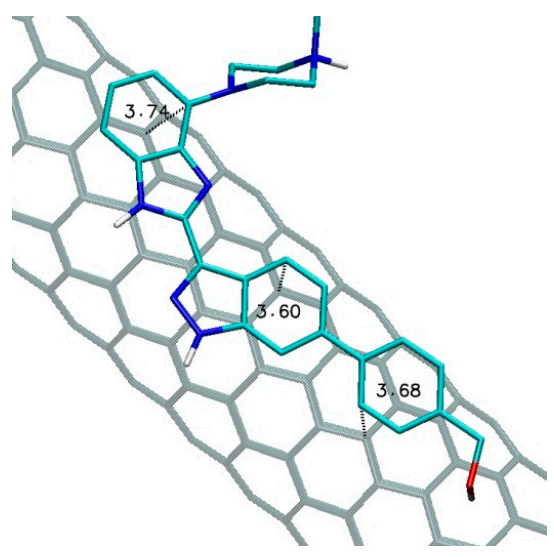

CNT_260

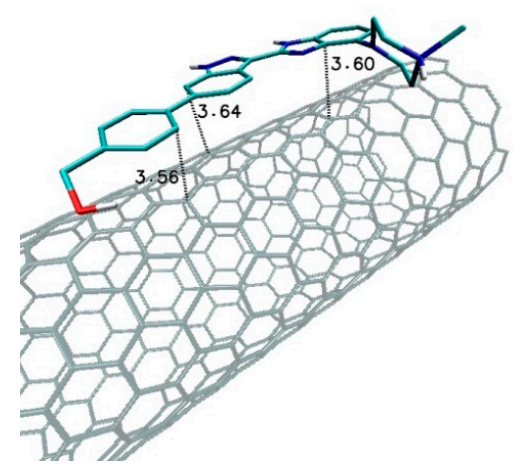

CNT_416

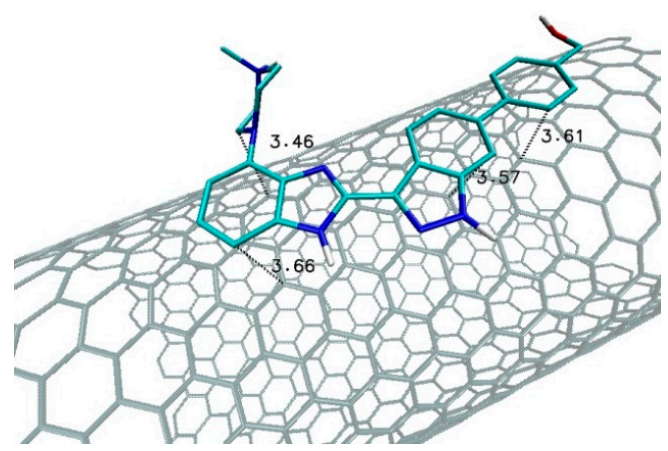

CNT_760

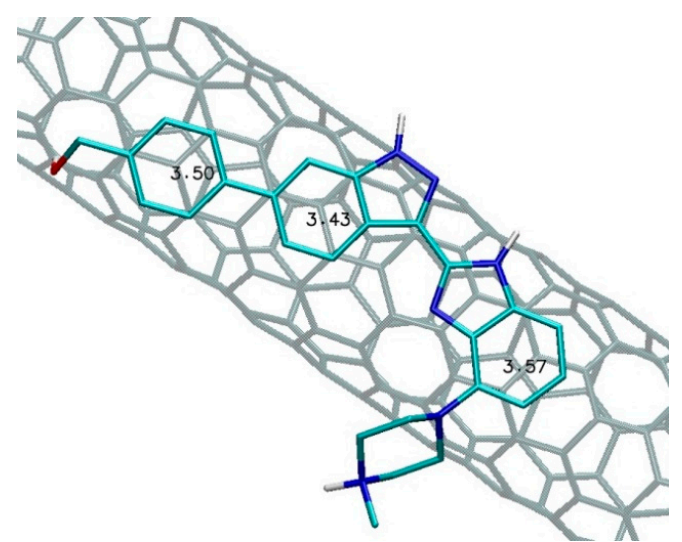

CNT_252

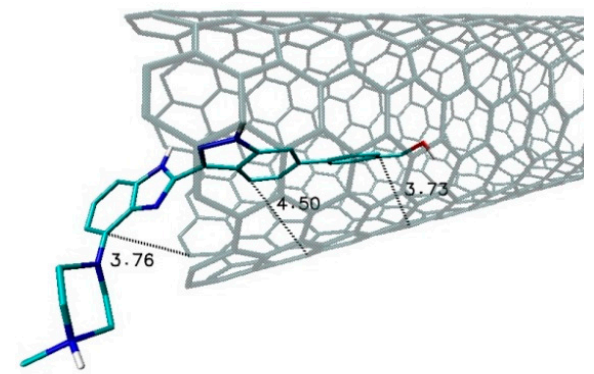

CNT_392

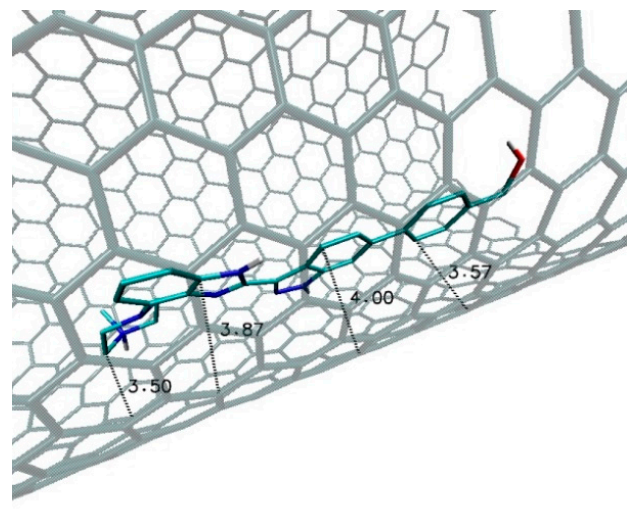

CNT_760

Figure 5. Graphic representation of complexes of the ligand molecule with chosen carbon nanotubes.

The last group of nanostructures utilized for the immobilization of the inhibitor molecule were cube rhombellanes and their homeomorphs. Values presented in Table 4 show that a significant group of considered nanocarriers exhibited a higher binding affinity towards the ligand molecule than the reference molecule $C_{60}$, and the observed differences were placed in the range of -0.7 to $-1.8 \mathrm{kcal} / \mathrm{mol}$. Calculated values of complex binding constants unambiguously show that such complexes were created much more efficiently, and the observed differences were placed in the range from 226 to $1986 \%$. The best binding properties relative to the ligand molecule among all cube rhombellane homeomorphs were shown by the 360a molecule. This nanomolecule consists of an aromatic core connected by ether bonds and eight external shell modules connected by ester bonds. A graphic representation of the 
complex created by this molecule is shown in Figure 6. The first and second aromatic system of the ligand molecule interacted by stacking interactions with one of the external modules of the nanocarrier, which was confirmed by the planar orientation of the considered aromatic systems and distance $3.56 \AA$. The next stabilizing impact was related to the presence of medium strength hydrogen bond created by a hydrogen atom $\mathrm{H} 4$ with oxygen from ester group. In this case, the occurrence of a hydrophobic interaction between the ligand fourth cyclic system and an aromatic system of the nanomolecule was possible. Much lower efficiency in complex creation was shown by the second structural isomer of the 360 molecule, namely form "b." The inner core of this nanomolecule had a different symmetry, which affected the structure of the external shell. Such structural changes meant that the best obtained complex conformation was characterized by a binding affinity lower by $0.7 \mathrm{kcal} / \mathrm{mol}$ than that of the first isomer of the 360 molecule. The complex of the ligand and $360 \mathrm{~b}$ molecule was maintained by a single stacking interaction created by the second aromatic system of the inhibitor molecule. There were also two hydrogen bonds observed; first of them, created by hydrogen $\mathrm{H} 2$, was a very weak one, as indicated by a length close to the limit of occurrence of hydrogen bonding, while the second one was a medium strength interaction created by hydrogen $\mathrm{H} 4$.

Table 4. Values of binding affinity $[\mathrm{kcal} / \mathrm{mol}]$ of ligand molecule relative to spherical nanosystems obtained during docking stage.

\begin{tabular}{|c|c|c|c|c|c|c|}
\hline \multirow{2}{*}{$\begin{array}{l}\text { Nanostructure } \\
\text { Name }\end{array}$} & \multicolumn{4}{|c|}{$\Delta \mathrm{G}[\mathrm{kcal} / \mathrm{mol}]$} & \multirow{2}{*}{$\begin{array}{c}\text { Binding } \\
\text { Constant }\left[K_{\max }\right]\end{array}$} & \multirow{2}{*}{$\begin{array}{l}\text { Difference of } K_{\max } \\
\text { Relative to } C_{60}[\%]\end{array}$} \\
\hline & MAX & MIN & AVERAGE & SD & & \\
\hline 144_ex_ex & -3.40 & -3.30 & -3.32 & 0.04 & 310.6 & -92.0 \\
\hline 144_in_ex & -3.80 & -3.80 & -3.80 & 0.00 & 610.2 & -84.4 \\
\hline 156_ex_ex & -3.60 & -3.60 & -3.60 & 0.00 & 435.3 & -88.9 \\
\hline 156_in_ex & -3.80 & -3.80 & -3.80 & 0.00 & 610.2 & -84.4 \\
\hline $308 \mathrm{a} 4$ & -6.60 & -6.40 & -6.50 & 0.09 & $68,843.7$ & 1662.4 \\
\hline $308 b 4$ & -6.50 & -6.40 & -6.41 & 0.03 & $58,151.8$ & 1388.7 \\
\hline $360 a$ & -6.70 & -6.30 & -6.49 & 0.15 & $81,501.4$ & 1986.5 \\
\hline $360 \mathrm{~b}$ & -6.00 & -5.90 & -5.98 & 0.04 & $25,006.8$ & 540.2 \\
\hline $372 \mathrm{AB}$ & -6.10 & -6.00 & -6.09 & 0.03 & $29,604.6$ & 657.9 \\
\hline 396 & -6.10 & -5.90 & -6.01 & 0.06 & $29,604.6$ & 657.9 \\
\hline 420 & -5.80 & -5.60 & -5.70 & 0.05 & $17,842.5$ & 356.8 \\
\hline 444 & -5.60 & -5.50 & -5.54 & 0.05 & $12,730.8$ & 225.9 \\
\hline 456 & -5.60 & -5.40 & -5.50 & 0.07 & $12,730.8$ & 225.9 \\
\hline ADA_132 & -5.80 & -5.70 & -5.72 & 0.04 & $17,842.5$ & 356.8 \\
\hline $\mathrm{C}_{60}$ & -4.90 & -4.90 & -4.90 & 0.00 & 3906.1 & 0.0 \\
\hline
\end{tabular}

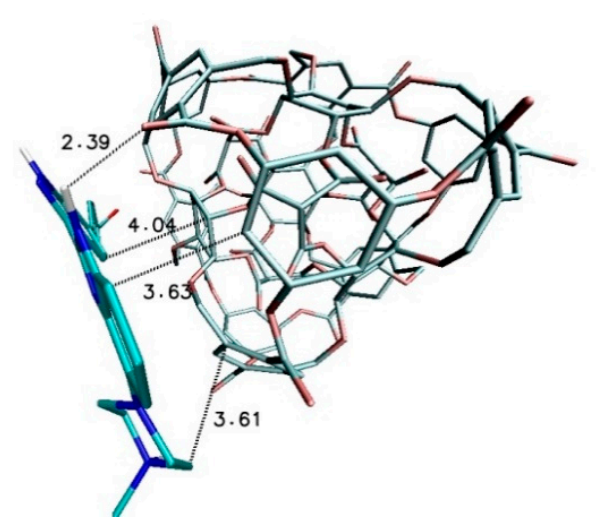

308 a

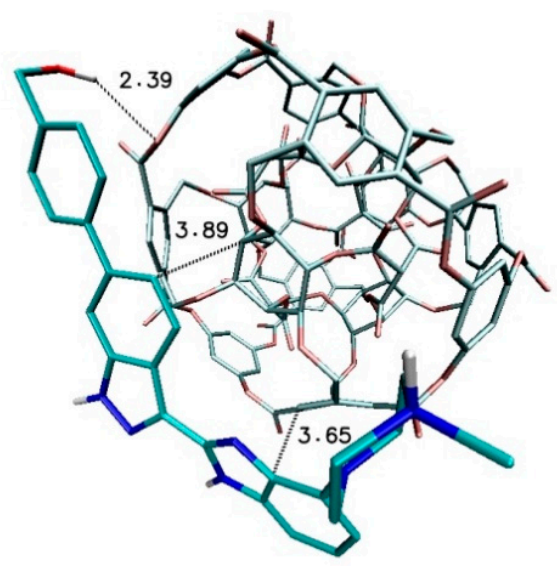

$3008 b$

Figure 6. Cont. 


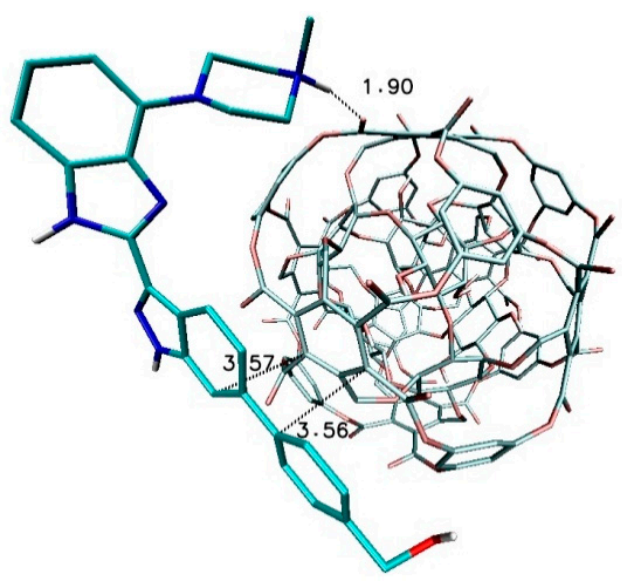

$360 \mathrm{a}$

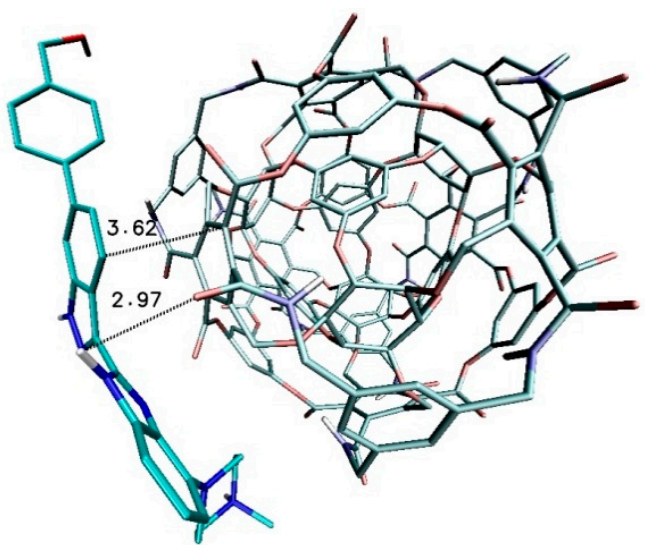

372

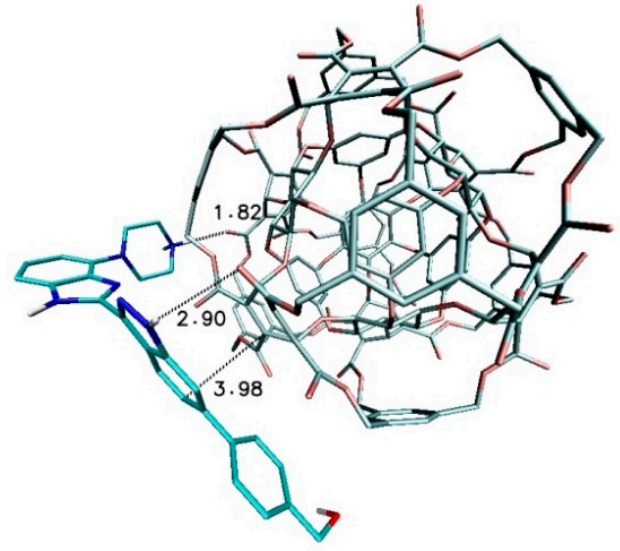

$360 \mathrm{~b}$

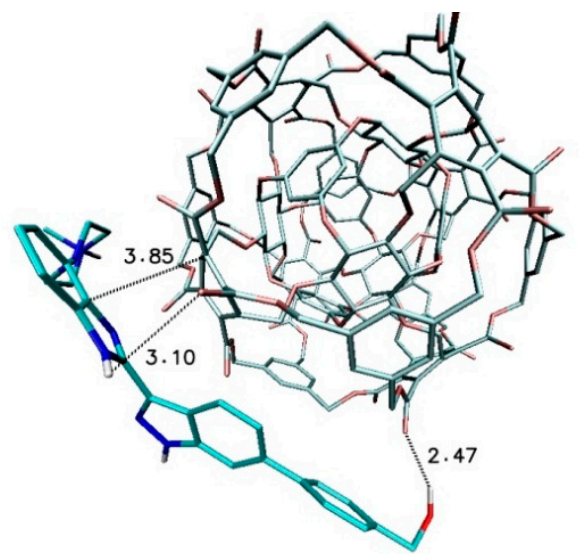

396

Figure 6. Graphic representation of complexes of ligand molecule with chosen cube rhombellane homeomorphs.

The next structures exhibiting significant affinity toward the considered ligand were the isomers of molecule $308(\mathrm{a}, \mathrm{b})$. The binding affinity for both structures reached values of at least $-1.6 \mathrm{kcal} / \mathrm{mol}$ higher than for the reference molecule. In both cases, the ligand molecule was involved in stacking interactions by the second and third aromatic system. One hydrogen bond was also observed in both complexes, namely, in the case of molecule 308a, it was a weak interaction created by hydrogen $\mathrm{H} 3$, while another weak interaction was created by hydrogen $\mathrm{H} 1$ in the case of molecule 308b. All discussed interactions can be observed in Figure 6.

The last two systems that are worth discussing are molecules 372 and 396, both of which exhibited similar binding affinity towards the ligand molecule equal to $-6.1 \mathrm{kcal} / \mathrm{mol}$. The complex of the former was stabilized by only one stacking interaction, occurring between the second aromatic ring of the ligand molecule and one of aromatic modules from nanocarrier external shell, and one weak hydrogen bond which was localized between hydrogen $\mathrm{H} 3$ and the oxygen from the amide group of the nanomolecule. The characteristics of interactions stabilizing the complex of molecule 396 were quite similar; in this case, the third aromatic system of the ligand molecule was involved in stacking interactions, along with one weak hydrogen bond, created by hydrogen $\mathrm{H} 1$.

\section{Conclusions}

The immobilization of compounds with pharmaceutical potential serves many functions, such as decreasing their toxicity, elongating their bioavailability, and increasing their pharmacological effect. The possibility of achieving such effects is strictly related to an appropriate choice of nanocarrier to 
be used in creation of such nanodrug. In this work, three different classes of possible nanostructures which could be used in immobilization of the considered ligand molecule were used. The characteristic structure of the inhibitor molecule, consisting of four cyclic systems, of which three are aromatic, clearly showed that stacking and hydrophobic interactions should play a dominant role in stabilization of interactions with such a molecule. The proposed groups of compounds made it possible to unambiguously verify this thesis. The highest values of both binding affinity and binding constant were found in the case of carbon nanotubes. Such nanosystems, being a rolled up graphene plane, provided a possibility of the occurance of stacking interactions with the ligand molecule rich in aromatic systems, exhibiting the ability to obtain a planar conformation. The analysis of systems with different diameter allowed the conclusion that the increase of this parameter, with an accompanying decrease in the curvature of the nanotube surface interacting with ligand molecule, clearly contributes to increased binding capacity of such nanosystems. Significant binding capacities of such systems are dictated by the considerable size of the considered nanostructures, which may be one of the factors limiting their applicability.

The next group of studied systems were functionalized derivatives of fullerene $\mathrm{C}_{60}$. The complexes of ligand molecules with such nanocarriers were characterized by much lower values of binding affinity than those created by CNT. This phenomenon can be largely explained by the size of the considered nanoparticles and the geometry of the molecules determining the exposure of the fullerene aromatic systems. The analyzed functionalized fullerenes clearly demonstrated the group of potential modifications that exhibit significant potential in increasing of binding capacity of $\mathrm{C}_{60}$ molecule. The addition of a single aromatic system on the surface of the fullerene considerably increased binding affinity toward the ligand molecule, relative to native fullerene. The addition of multiple aromatic systems contributed to the achievement of even better binding abilities of the considered nanosystems. Another class of modifications were substituents containing hydrogen bond donors and acceptors; however, the observed effects were less satisfactory, which was due to lower affinity values relative to nanostructures with aromatic substituents and the lack of any conformation of ligands that ensured the formation of hydrogen bonds. Such observations clearly confirm that in the case of this particular ligand molecule, the most important interactions are stacking interactions between aromatic moieties.

The last group of considered nanosytems, namely cube rhombellane homeomorphs, showed the lowest binding capacity relative to the ligand molecule. A large group of proposed compounds exhibited satisfying binding affinity towards the ligand molecule. The binding capacity of these nanostructures is strictly related with the structure of the external shell of these molecules. The example of molecules 360a and 360b clearly shows that two structural isomers can exhibit significant differences in this field.

Supplementary Materials: The following are available online at http://www.mdpi.com/2073-8994/11/8/980/s1, Table S1: Description of functionalized $\mathrm{C}_{60}$ fullerene derivatives (FF_X) used during docking stage, Table S2: Description of cube rhombellanes (Core) and functionalized structures with external layer (C-rbl). Value chem. type define chemical bond type characteristic for specific layer of considered molecule (core-molecular core; ex. Shell-external layer of the nanomolecule).

Author Contributions: Conceptualization, P.C.; Methodology, P.C.; Software, P.C.; Validation, P.C.; Formal Analysis, P.C.; Investigation, P.C.; Resources, P.C. and B.S.; Data Curation, P.C.; Writing-Original Draft Preparation, P.C.; Writing-Review \& Editing, P.C. and B.S.; Visualization, P.C.; Supervision, P.C.; Project Administration, P.C.; Funding Acquisition, P.C.

Funding: This research received no external funding.

Acknowledgments: Thank you to the Professor MV Diudea for sharing the structures. This research was supported by PL-Grid Infrastructure (http://www.plgrid.pl/en).

Conflicts of Interest: The authors declare that there are no conflicts of interest.

\section{References}

1. Kunikata, T.; Tatefuji, T.; Aga, H.; Iwaki, K.; Ikeda, M.; Kurimoto, M. Indirubin inhibits inflammatory reactions in delayed-type hypersensitivity. Eur. J. Pharmacol. 2000, 410, 93-100. [CrossRef] 
2. Kim, S.-A.; Kwon, S.-M.; Kim, J.-A.; Kang, K.W.; Yoon, J.-H.; Ahn, S.-G. 5'-Nitro-indirubinoxime, an indirubin derivative, suppresses metastatic ability of human head and neck cancer cells through the inhibition of Integrin $\beta 1 / F A K / A k t$ signaling. Cancer Lett. 2011, 306, 197-204. [CrossRef] [PubMed]

3. Williams, S.P.; Nowicki, M.O.; Liu, F.; Press, R.; Godlewski, J.; Abdel-Rasoul, M.; Kaur, B.; Fernandez, S.A.; Chiocca, E.A.; Lawler, S.E. Indirubins decrease glioma invasion by blocking migratory phenotypes in both the tumor and stromal endothelial cell compartments. Cancer Res. 2011, 71, 5374-5380. [CrossRef] [PubMed]

4. Shin, E.-K.; Kim, J.-K. Indirubin derivative E804 inhibits angiogenesis. BMC Cancer 2012, 12, 164. [CrossRef] [PubMed]

5. Martin, L.; Magnaudeix, A.; Wilson, C.M.; Yardin, C.; Terro, F. The new indirubin derivative inhibitors of glycogen synthase kinase-3, 6-BIDECO and 6-BIMYEO, prevent tau phosphorylation and apoptosis induced by the inhibition of protein phosphatase-2A by okadaic acid in cultured neurons. J. Neurosci. Res. 2011, 89, 1802-1811. [CrossRef]

6. Czeleń, P. Molecular dynamics study on inhibition mechanism of CDK-2 and GSK-3 $\beta$ by CHEMBL272026 molecule. Struct. Chem. 2016, 27, 1807-1818. [CrossRef]

7. Czeleń, P. Inhibition mechanism of CDK-2 and GSK-3 $\beta$ by a sulfamoylphenyl derivative of indoline-a molecular dynamics study. J. Mol. Model. 2017, 23, 230. [CrossRef]

8. Marko, D.; Schätzle, S.; Friedel, A.; Genzlinger, A.; Zankl, H.; Meijer, L.; Eisenbrand, G. Inhibition of cyclin-dependent kinase 1 (CDK1) by indirubin derivatives in human tumour cells. Br. J. Cancer 2001, 84, 283-289. [CrossRef]

9. Hoessel, R.; Leclerc, S.; Endicott, J.A.; Nobel, M.E.M.; Lawrie, A.; Tunnah, P.; Leost, M.; Damiens, E.; Marie, D.; Marko, D.; et al. Indirubin, the active constituent of a Chinese antileukaemia medicine, inhibits cyclin-dependent kinases. Nat. Cell Biol. 1999, 1, 60-67. [CrossRef]

10. Xiao, Z.; Hao, Y.; Liu, B.; Qian, L. Indirubin and Meisoindigo in the Treatment of Chronic Myelogenous Leukemia in China. Leuk. Lymphoma 2002, 43, 1763-1768. [CrossRef]

11. Lee, M.-Y.; Liu, Y.-W.; Chen, M.-H.; Wu, J.-Y.; Ho, H.-Y.; Wang, Q.-F.; Chuang, J.-J. Indirubin-3'-monoxime promotes autophagic and apoptotic death in JM1 human acute lymphoblastic leukemia cells and K562 human chronic myelogenous leukemia cells. Oncol. Rep. 2013, 29, 2072-2078. [CrossRef]

12. Czeleń, P.; Szefler, B. Molecular dynamics study of the inhibitory effects of ChEMBL474807 on the enzymes GSK-3 $\beta$ and CDK-2. J. Mol. Model. 2015, 21, 74. [CrossRef]

13. De Jong, W.H.; Borm, P.J.A. Drug delivery and nanoparticles:applications and hazards. Int. J. Nanomedicine 2008, 3, 133-149. [CrossRef]

14. Gao, Z.; Zhang, L.; Sun, Y. Nanotechnology applied to overcome tumor drug resistance. J. Control. Release 2012, 162, 45-55. [CrossRef]

15. Morgen, M.; Bloom, C.; Beyerinck, R.; Bello, A.; Song, W.; Wilkinson, K.; Steenwyk, R.; Shamblin, S. Polymeric Nanoparticles for Increased Oral Bioavailability and Rapid Absorption Using Celecoxib as a Model of a Low-Solubility, High-Permeability Drug. Pharm. Res. 2012, 29, 427-440. [CrossRef]

16. Turov, V.V.; Chehun, V.F.; Barvinchenko, V.N.; Krupskaya, T.V.; Prylutskyy, Y.I.; Scharff, P.; Ritter, U. Low-temperature 1H-NMR spectroscopic study of doxorubicin influence on the hydrated properties of nanosilica modified by DNA. J. Mater. Sci. Mater. Med. 2011, 22, 525-532. [CrossRef]

17. Schuetze, C.; Ritter, U.; Scharff, P.; Fernekorn, U.; Prylutska, S.; Bychko, A.; Rybalchenko, V.; Prylutskyy, Y. Interaction of $\mathrm{N}$-fluorescein-5-isothiocyanate pyrrolidine-C60 with a bimolecular lipid model membrane. Mater. Sci. Eng. C 2011, 31, 1148-1150. [CrossRef]

18. Evstigneev, M.P.; Buchelnikov, A.S.; Voronin, D.P.; Rubin, Y.V.; Belous, L.F.; Prylutskyy, Y.I.; Ritter, U. Complexation of $\mathrm{C}_{60}$ Fullerene with Aromatic Drugs. ChemPhysChem 2013, 14, 568-578. [CrossRef]

19. Qiao, R.; Roberts, A.P.; Mount, A.S.; Klaine, S.J.; Ke, P.C. Translocation of $\mathrm{C}_{60}$ and Its Derivatives Across a Lipid Bilayer. Nano Lett. 2007, 7, 614-619. [CrossRef]

20. Prylutska, S.; Bilyy, R.; Overchuk, M.; Bychko, A.; Andreichenko, K.; Stoika, R.; Rybalchenko, V.; Prylutskyy, Y.; Tsierkezos, N.G.; Ritter, U. Water-soluble pristine fullerenes $\mathrm{C}_{60}$ increase the specific conductivity and capacity of lipid model membrane and form the channels in cellular plasma membrane. J. Biomed. Nanotechnol. 2012, 8, 522-527. [CrossRef]

21. Prylutska, S.V.; Grynyuk, I.I.; Grebinyk, S.M.; Matyshevska, O.P.; Prylutskyy, Y.I.; Ritter, U.; Siegmund, C.; Scharff, P. Comparative study of biological action of fullerenes $\mathrm{C}_{60}$ and carbon nanotubes in thymus cells. Materwiss. Werksttech. 2009, 40, 238-241. [CrossRef] 
22. Johnston, H.J.; Hutchison, G.R.; Christensen, F.M.; Aschberger, K.; Stone, V. The Biological Mechanisms and Physicochemical Characteristics Responsible for Driving Fullerene Toxicity. Toxicol. Sci. 2010, 114, 162-182. [CrossRef]

23. Andrievsky, G.; Klochkov, V.; Derevyanchenko, L. Is the $\mathrm{C}_{60}$ Fullerene Molecule Toxic?! Fuller. Nanotub. Carbon Nanostructures 2005, 13, 363-376. [CrossRef]

24. Satoh, M.; Takayanagi, I. Pharmacological studies on fullerene $\left(\mathrm{C}_{60}\right)$, a novel carbon allotrope, and its derivatives. J. Pharmacol. Sci. 2006, 100, 513. [CrossRef]

25. Yin, J.-J.; Lao, F.; Fu, P.P.; Wamer, W.G.; Zhao, Y.; Wang, P.C.; Qiu, Y.; Sun, B.; Xing, G.; Dong, J.; et al. The scavenging of reactive oxygen species and the potential for cell protection by functionalized fullerene materials. Biomaterials 2009, 30, 611-621. [CrossRef]

26. Partha, R.; Conyers, J.L. Biomedical applications of functionalized fullerene-based nanomaterials. Int. J. Nanomedicine 2009, 4, 261-275.

27. Echalier, A.; Hole, A.J.; Lolli, G.; Endicott, J.A.; Noble, M.E.M. An inhibitor's-eye view of the ATP-binding site of CDKs in different regulatory states. ACS Chem. Biol. 2014, 9, 1251-1256. [CrossRef]

28. Simon, J.; Flahaut, E.; Golzio, M. Overview of Carbon Nanotubes for Biomedical Applications. Materials 2019, 12, 624. [CrossRef]

29. Lucente-Schultz, R.M.; Moore, V.C.; Leonard, A.D.; Price, B.K.; Kosynkin, D.V.; Lu, M.; Partha, R.; Conyers, J.L.; Tour, J.M. Antioxidant Single-Walled Carbon Nanotubes. J. Am. Chem. Soc. 2009, 131, 3934-3941. [CrossRef]

30. Czeleń, P.; Szefler, B. The Immobilization of Oxindole Derivatives with Use of Cube Rhombellane Homeomorphs. Symmetry 2019, 11, 900. [CrossRef]

31. Szefler, B.; Czeleń, P. Docking of Cisplatin on Fullerene Derivatives and Some Cube Rhombellane Functionalized Homeomorphs. Symmetry 2019, 11, 874. [CrossRef]

32. Szefler, B.; Czeleń, P.; Diudea, M.V. Docking of indolizine derivatives on cube rhombellane functionalized homeomorphs. Stud. Univ. Babes-Bolyai Chem. 2018, 63, 7-18. [CrossRef]

33. Diudea, M.V.; Lungu, C.N.; Nagy, C.L.; Diudea, M.V.; Lungu, C.N.; Nagy, C.L. Cube-Rhombellane Related Structures: A Drug Perspective. Molecules 2018, 23, 2533. [CrossRef]

34. CHEMBL database release 24.1. 2018. Available online: https://www.ebi.ac.uk/chembl/ (accessed on 2 February 2014).

35. Kim, K.-H.; Ko, D.K.; Kim, Y.-T.; Kim, N.H.; Paul, J.; Zhang, S.-Q.; Murray, C.B.; Acharya, R.; Kim, Y.H.; DeGrado, W.F.; et al. Protein-directed self-assembly of a fullerene crystal. Nat. Commun. 2016, 7, 11429. [CrossRef]

36. PubChem. Available online: https://pubchem.ncbi.nlm.nih.gov/ (accessed on 5 May 2019).

37. Humphrey, W.; Dalke, A.; Schulten, K. VMD: Visual molecular dynamics. J. Mol. Graph. 1996, 14, 33-38. [CrossRef]

38. Trott, O.; Olson, A.J. AutoDock Vina: Improving the speed and accuracy of docking with a new scoring function, efficient optimization, and multithreading. J. Comput. Chem. 2010, 31, 455-461. [CrossRef]

39. Bartashevich, E.V.; Potemkin, V.A.; Grishina, M.A.; Belik, A.V. A Method for Multiconformational Modeling of the Three-Dimensional Shape of a Molecule. J. Struct. Chem. 2002, 43, 1033-1039. [CrossRef]

(C) 2019 by the authors. Licensee MDPI, Basel, Switzerland. This article is an open access article distributed under the terms and conditions of the Creative Commons Attribution (CC BY) license (http://creativecommons.org/licenses/by/4.0/). 